\title{
Optimization of the periodontal attachment before orthodontic treatment
}

\author{
S. Mouraret ${ }^{1}$, J.-P. Forestier ${ }^{2}$ \\ 1 Private practice specializing exclusively in periodontology and implantology \\ 2 MCU-PH Orthodontics. Paris VII, Hôpital Pitié-Salpêtrière
}

\section{SUMMARY}

\begin{abstract}
Severe bone loss due to periodontal disease is often associated with migration and dental malpositions and requires orthodontic treatment. After conventional periodontal treatment, which is essential before orthodontic treatment, scaring of the attachment of the periodontal ligament occurs. Recent advances in the field allow us to understand the mechanisms of periodontal healing better, and can result in regeneration of the periodontal ligament. Surgical regeneration procedures in association with orthodontic treatment are complementary. They optimize the support, allowing better long-term results.
\end{abstract}

\section{KEYWORDS}

Periodontitis, advanced bone loss, regeneration, orthodontic movement, migration

\section{INTRODUCTION}

With the development of esthetic orthodontic techniques, more and more adult patients are choosing to undertake orthodontic treatment. This choice is often motivated by dental migrations and malpositions, the consequences of periodontal diseases, in which orthodontic treatment is essential to obtain an improvement in the distribution of constraints and access to hygiene.

Periodontal loss due to periodontitis remains relatively common: $95.4 \%$ adults in France have periodontal attachment loss, and $50 \%$ adults suffer from severe attachment loss $(\geq 5 \mathrm{~mm})^{1}$. The evolution of implanted prosthetics systems allows the replacement of teeth lost due to periodontal diseases. However, tooth retention is always preferable from an esthetic, psychological, and functional point of view, especially in view of the latest data on implant complications. ${ }^{13}$

Recent developments in regenerative periodontal therapy currently allows us to optimize the quality of dental support before orthodontic displacement, and to obtain better durability and stability of tissues.

\section{Address for correspondence:}




\section{REPAIR OR REGENERATION OF THE PERIODONTAL ATTACHMENT}

The treatment of periodontal diseases begins with noninvasive therapies aimed at decreasing bacterial load and suppressing inflammation.

They may be associated with surgical procedures when deep pockets persist ( $>5 \mathrm{~mm}$ ) accompanied by bleeding ${ }^{6}$.

However, nonsurgical procedures, such as the sanitation flap, result in scar tissue formation, which will result histologically in the formation of a long-junctional epithelial cells ${ }^{9}$.
The purpose of any treatment is to restore the entity back to its natural state. Thus, regeneration procedures have been proposed.

Periodontal regeneration is defined as the formation of new collagen fibers inserted into a neo-cement on one side and neo-formed alveolar bone on the other side on a previously infected root surface ${ }^{10}$.

Among the methods of regeneration used, the use of enamel matrix-derived proteins (EMD) is well documented in several systematic reviews $s^{4,5,17}$.

\section{ORTHODONTICS AND PERIODONTAL ATTACHMENTS}

Orthodontic dental movements in patients with a thin periodontium can be successfully performed in the absence of inflammation and with good plaque control ${ }^{3}$.
However, Polson et al. show that after periodontal healing using the long epithelial attachment type, the tooth movement toward the defect decreased the bone lesion but did not

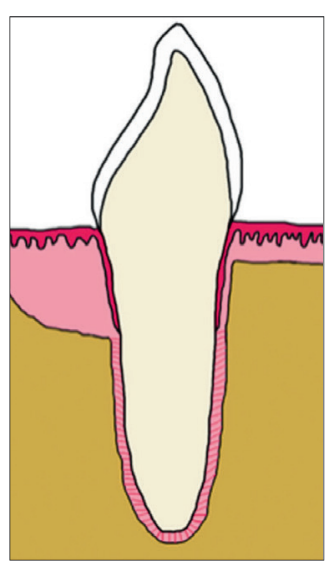

b) After orthodontic treatment, closure of the intraosseous defect is observed, but the long epithelial attachment still shows scarring.

Figure 1

No effect of orthodontic treatment on the periodontal attachment. 


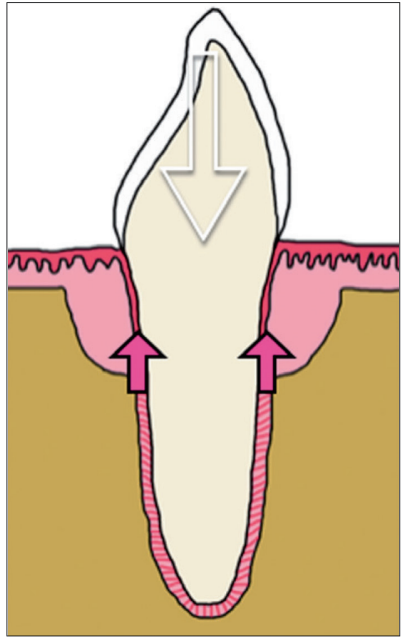

After conventional periodontal treatment.

Figure 2

Regeneration of periodontal attachment in the intrusion movements.

modify the type of attachment, which stayed the same ${ }^{14}$.
Melsen et al., on the other hand, show that decreased periodontal orthodontic movement may promote periodontal regeneration and bone apposition in intrusion movements with low and constant periodontal pressures ${ }^{11,12}$ These clinical findings are confirmed by animal experiments ${ }^{2,15}$.

Tissue regeneration techniques induced with EMD allow attachment gains of $1.08 \mathrm{~mm}$ compared to the control group at 1 year and of $1.2 \mathrm{~mm}$ when EMD is added to autogenous bone ${ }^{18}$, which represents a significant gain at the root level.

Grade-2 inter-radicular lesions are also of interest. ${ }^{8}$

These results can be maintained over time as shown by Sculean et al. with a significant difference in attachment gain of $2.9 \mathrm{~mm}$ for the regeneration group compared to $1.8 \mathrm{~mm}$ for the 10 year sanitation flap group16

\section{REGENERATION OF THE ATTACHMENT BEFORE ORTHODONTIC TREATMENT}

Faced with such clinical situations, it is better to strengthen the periodontal attachment before initiating the ortho- dontic treatment to optimize the quality of the attachment and the durability of our treatments.

\section{CLINICAL CASE}

Mrs. E.T. presented to us for a periodontology consultation tooth mobility.

She is 56 years old, a nonsmoker, has moderate stress, parents who had lost their teeth at a young age, and has mild osteopenia. Her rheumatologist plans to treat her with bisphosphonates after the end of her dental treatment.
After medical examination and history, the patient receives a complete periodontal examination, oral hygiene and scaling, and root resurfacing over four sessions.

At the initial examination, the patient had average pockets of 8-14 $\mathrm{mm}$, with grade-2 and grade-3 inter-root lesions, 
increased bleeding upon probing, and increased plaque indices.

After 8 weeks, periodontal revaluation was performed. A general and individual prognosis of each tooth was performed. Only tooth 16 has a bad prognosis and 26 a very uncertain prognosis. A treatment plan was drawn up with the orthodontic specialist (Dr. Jean-Paul Forestier) and the results were explained to the patient.

The periodontal objective was to establish a stable and perennial situation, in agreement with the criteria of periodontal health allowing orthodontic movement: absence of inflammation, absence of pockets $>4 \mathrm{~mm}$, and absence of inter-root lesions. ${ }^{7}$

Surgical corrective phases with induced tissue regeneration techniques were programmed on all sectors except the mandibular incisors. Tooth 16 was extracted in the same procedure.

After periodontal healing, we obtained a satisfactory overall result in agreement with Hujoel 7 except on tooth 26, which still has a deep grade-2 inter-root lesion with inflammation, which we decided to extract before the start of orthodontic treatment.

Orthodontic anchors were employed at the request of Dr. Jean-Paul Forestier, after which the orthodontic treatment began.

During this treatment, the patient underwent supportive periodontal therapy before each treatment session and we performed sub-sinus grafts on the sites of 16 and 26.
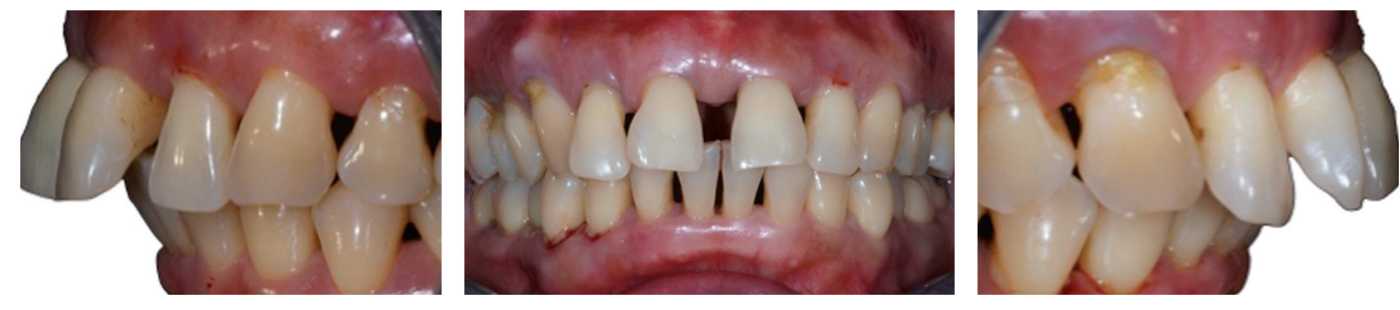

Figure 3

Initial Intraoral Photos.

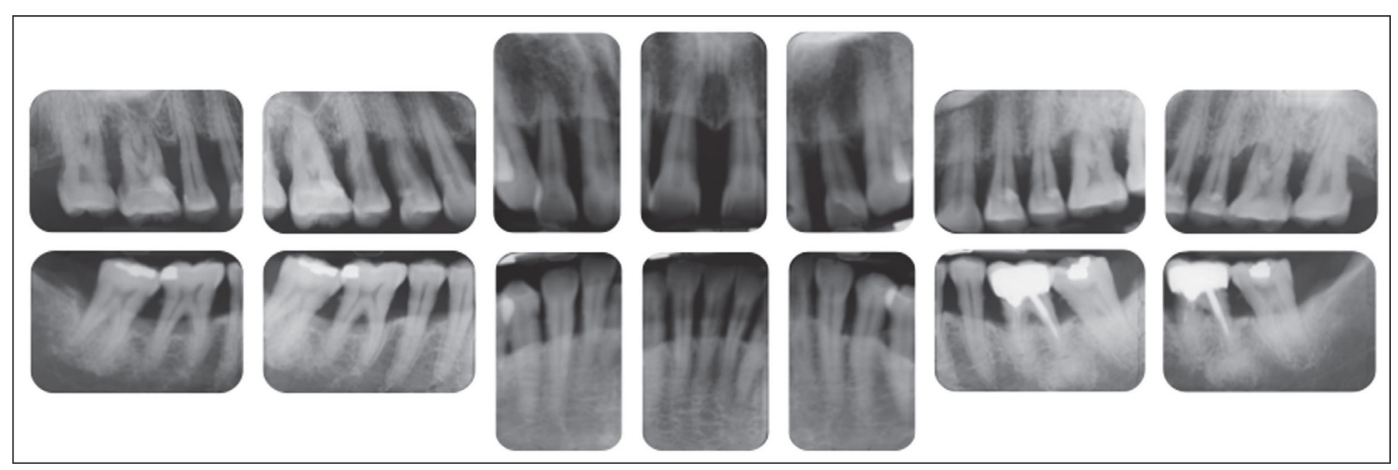

Figure 4

Initial $X$-ray results. 


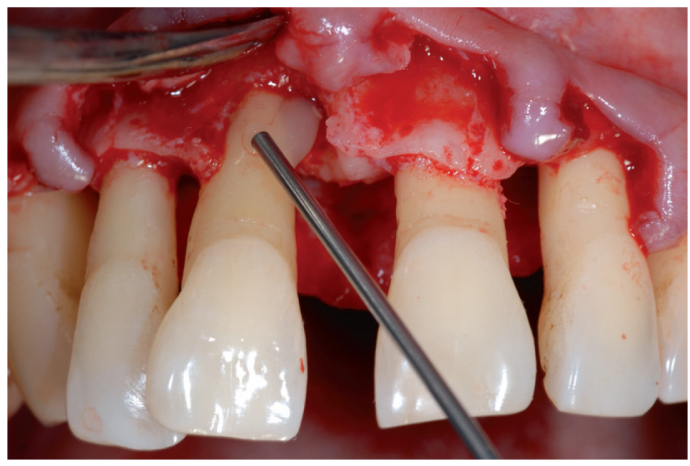

Figure 5:

Preoperative image of induced tissue regeneration surgery.
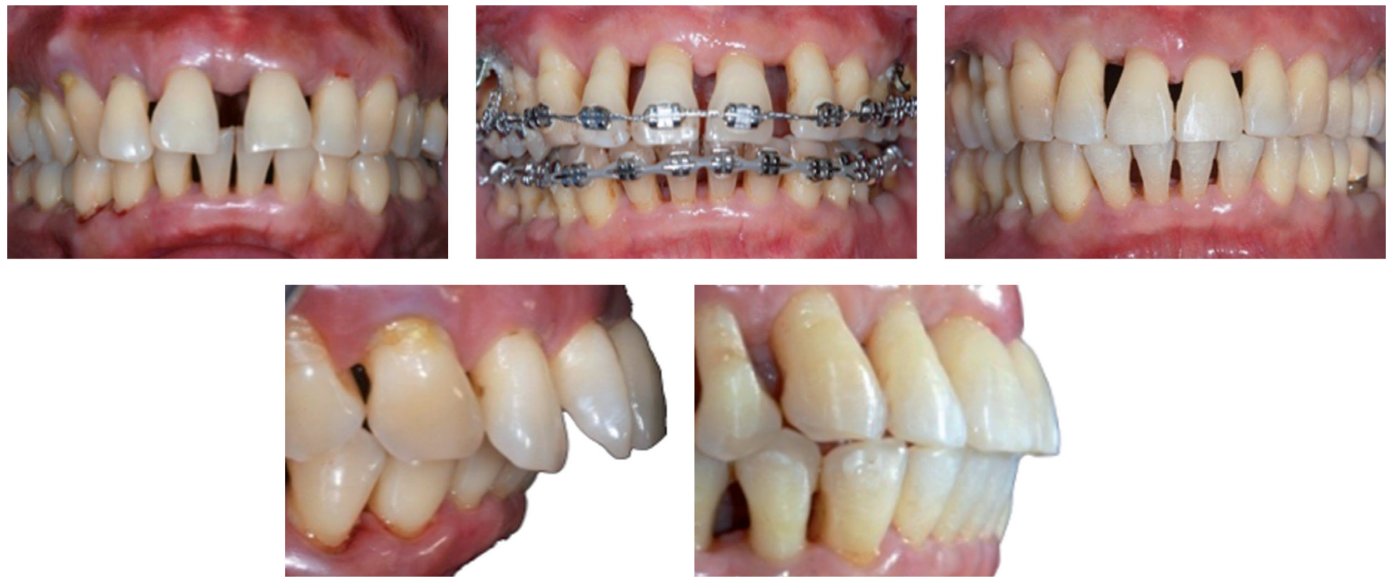

Figure 6

Preorthodontic, intraorthodontic, and postorthodontic treatment photos.

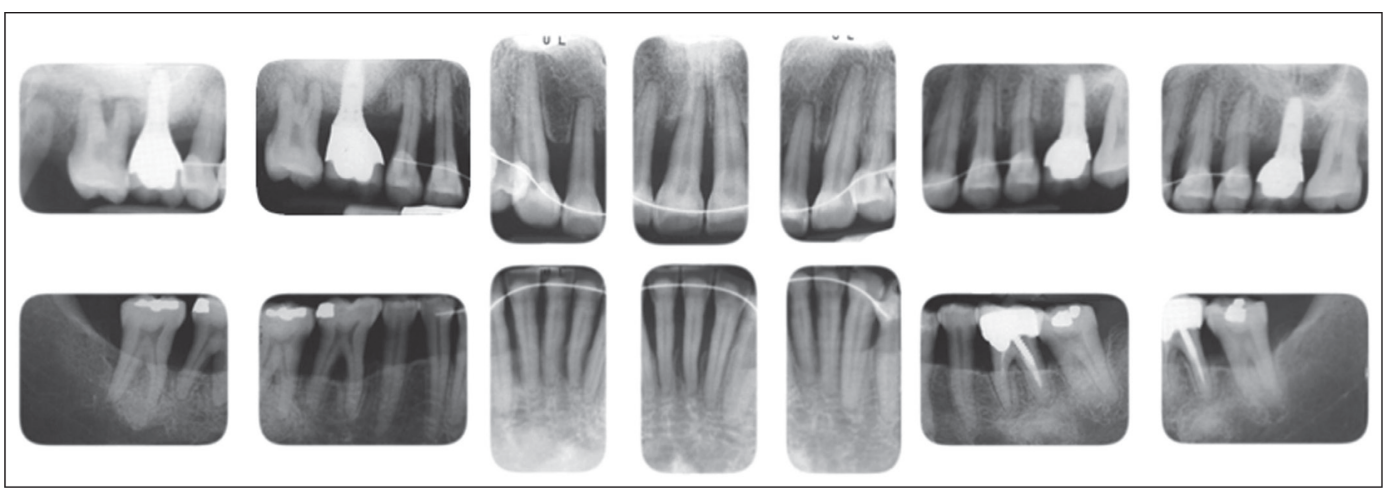

Figure 7

$X$-ray results after treatment. 

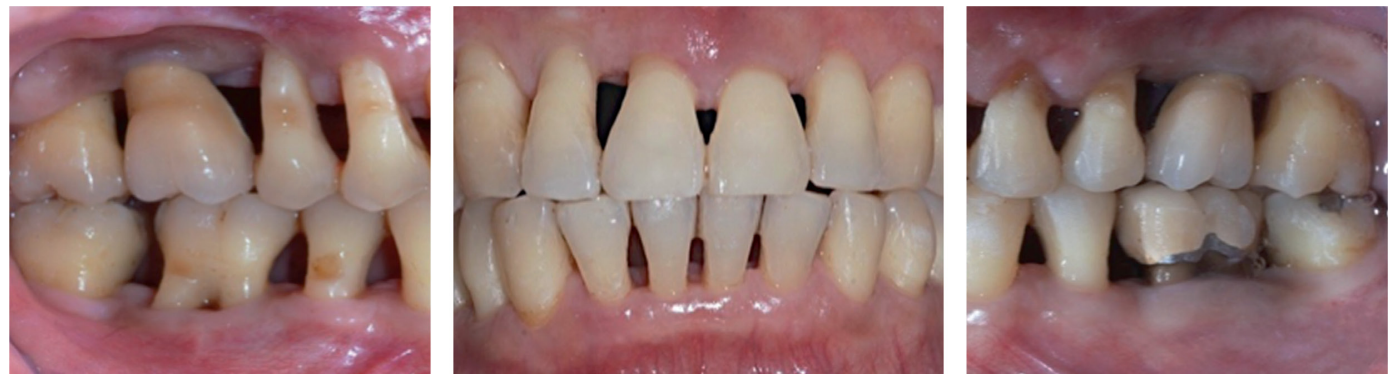

Figure 8

Intraoral photos after 5 years.

In agreement with the orthodontist, we placed implants in 16 and 26, 3 months before the end of the orthodontic treatment.

With the treatment completed, we were able to put the caps directly on the implants, then remove the device and perform the restorations.

The patient has received a periodontal checkup every 3 months since September 2011.

\section{CONCLUSION}

Severe alveolysis due to periodontal disease is common and can be treated.

Tooth preservation is often the best solution. In addition, it does not exclude an alternative prosthetic solution in the future.

The new treatment strategies make it possible to optimize the periodontal support by forming a real regenerated attachment. The clinical results are better in terms of tether gain than conventional techniques.

Orthodontic treatment with weak and constant periodontal pressures also appears to improve periodontal attachment, particularly in intrusion movements.

This surgical stimulation of the periodontal attachment, in combination with orthodontic treatment and impeccable hygiene, is a complementary technique particularly well indicated in cases of a severe thin periodontium in a motivated patient.

\section{Conflict of Interest}

The authors declare that there is no conflict of interest.

\section{BIBLIOGRAPHY}

1. Bourgeois D, Bouchard P, Mattout C. Epidemiology of periodontal status in dentate adults in France, 2002-2003. J Periodontal Res 2007;42(3):219-27. 
2. Diedrich $P$, Fritz $U$, Kinzinger G, Angelakis J. Movement of periodontally affected teeth after guided tissue regeneration (GTR)--an experimental pilot study in animals. J Orofac Orthop 2003;64(3):214-27.

3. Ericsson I, Thilander B, Lindhe J, Okamoto $\mathrm{H}$. The effect of orthodontic tilting movements on the peri odontal tissues of infected and non-infected dentitions in dogs. J Clin Periodontol 1977;4(4):278-93.

4. Esposito M, Grusovin MG, Papanikolaou N, Coulthard P, Worthington HV. Enamel matrix derivative (Emdogain $(R))$ for periodontal tissue regeneration in intrabony defects. Cochrane Database Syst Rev 2009;(4):CD003875.

5. Giannobile WV, Somerman MJ. Growth and amelogenin-like factors in periodontal wound healing. A systematic review. Ann Periodontol 2003;8(1):193-204.

6. Heitz-Mayfield LJ, Trombelli L, Heitz F, Needleman I, Moles D. A systematic review of the effect of surgical debridement vs non-surgical debridement for the treatment of chronic periodontitis. J Clin Periodontol 2002;29 Suppl 3:92-102; discussion 160-2.

7. Hujoel PP. Endpoints in periodontal trials: the need for an evidence-based research approach. Periodontol 2000 2004;36:196-204.

8. Jepsen $\mathrm{S}$, et al. A randomized clinical trial com paring enamel matrix derivative and membrane treatment of buccal Class II furcation involvement in mandibular molars. Part I: Study design and results for primary outcomes. J Periodontol 2004;75(8):1150-60.

9. Listgarten MA. Normal development, structure, physiology and repair of gingival epithelium. Oral Sci Rev 1972;1:3-67.

10. Melcher AH. On the repair potential of periodontal tissues. J Periodontol 1976;47(5):256-60.

11. Melsen B, Agerbaek N, Eriksen J, Terp S. New attach ment through periodontal treatment and orthodontic intrusion. Am J Orthod Dentofacial Orthop 1988;94(2):104-16.

12. Melsen B. Tissue reaction to orthodontic tooth movement--a new paradigm. Eur $\mathrm{J}$ Orthod 2001;23(6):671-81.

13. Mombelli A, Müller N, Cionca N. The epidemiology of peri-implantitis. Clin Oral Implants Res 2012;23 Suppl 6:67-76.

14. Polson A, Caton J, Polson AP, Nyman S, Novak J, Reed B. Periodontal response after tooth movement into intra bony defects. J Periodontol 1984;55(4):197-202.

15. Reichert C, Deschner J, Kasaj A, Jäger A. Guided Tissue Regeneration and Orthodontics. A Review of the Literature. J Orofac Orthop 2009;70:6-19.

16. Sculean A, Kiss A, Miliauskaite A, Schwarz F, Arweiler NB, Hannig M. Ten-year results following treatment of intra-bony defects with enamel matrix proteins and guided tissue regeneration. J Clin Periodontol 2008;35(9):817-24.

17. Trombelli L, Heitz-Mayfield LJ, Needleman I, Moles D, Scabbia A. A systematic review of graft materials and biological agents for periodontal intraosseous defects. J Clin Periodontol 2002;29 Suppl 3:117-35.

18. Yilmaz S, Cakar G, Yildirim B, Sculean A. Healing of two and three wall intrabony periodontal defects following treatment with an enamel matrix derivative combined with autogenous bone. J Clin Periodontol 2010;37:544-550. 